\title{
High Frequency Charging Techniques- Grid Connected Power Generation Using Switched Reluctance Generator
}

\author{
S. Sridharan, S. Sudha \\ Department of Electronics and Communication Engineering, Easwari Engineering College, Chennai, India \\ Email: sridharsubbiah@gmail.com, sudha76s@yahoo.com
}

How to cite this paper: Sridharan, S. and Sudha, S. (2016) High Frequency Charging Techniques-Grid Connected Power Generation Using Switched Reluctance Generator. Circuits and Systems, 7, 4308-4321. http://dx.doi.org/10.4236/cs.2016.714352

Received: May 8, 2016

Accepted: May 25, 2016

Published: December 22, 2016

Copyright $\odot 2016$ by authors and Scientific Research Publishing Inc. This work is licensed under the Creative Commons Attribution International License (CC BY 4.0).

http://creativecommons.org/licenses/by/4.0/ (c) (i) Open Access

\section{Abstract}

Power generation becomes the need of developed, developing and under developed countries to meet their increasing power requirements. When affordability increases their requirement of power increases, this happens when increased per capita consumption. The existing power scenario states that highest power is produced using firing of coals called thermal energy. A high efficiency Switched Reluctance Generator (SRG) based high frequency switching scheme to enhance the output for grid connectivity is designed, fabricated and evaluated. This proposed method generates the output for the low wind speed. It provides output at low speed because of multi-level DC-DC converter and storage system. It is an efficient solution for low wind power generation. The real time readings and results are discussed.

\section{Keywords}

Switched Reluctance Motor (SRM), Power Quality (PQ), On Screen Data Logger (OSDL), Switched Reluctance Generator (SRG), Battery Energy Storage System (BESS), Double-Fed Induction Generator (DFIG), Generator Company (GENCO)

\section{Introduction}

Power scenario in India states that more than $70.7 \%-73.0 \%$ of the net power is produced by means of thermal power plant and around $14 \%-16 \%$ is produced by hydro power plant. Approximately $1.9 \%-2.8 \%$ of the net power is contributed by atomic power plants, and renewable energies contribution leads approximately $6 \%-8 \%$, direct diesel utilization based power generation leads $1 \%$ - 
$2 \%$ of the net power. The contribution of micro power generations could be approximately $1 \%-2 \%$.

The scenario to be reconfigured to save coal and disappearing natural inputs by increasing power generation from renewable energy sources like wind, solar, etc. Based on the data given by the Ministry of Power-India, for the year 2016, it is clearly indicates the above statistical values, the $70 \%$ of the net energy is polluting the environment and at the earliest coal may be disappeared, because, coal is available for another 80 - 90 years provided that the consumption leads to the existing scenario. It is essential now we need to produce energy from renewable sources for conservation of natural resources.

Installation of more wind forms may provide an efficient solution for the present, in existing scenario contribution of the wind forms are very low because of the cost, efficiency, maintenance, grid connectivity and periodic analysis make the system inefficient. It can be solved using generators like SRG used as a wind power generator with appropriate control mechanism and grid connecting circuits [1]. A grid connected switched reluctance generator based wind energy harvesting system is designed, constructed and verified for real time application.

Switched Reluctance Machine plays a major role in the industry over 30 years because of its unique features like control methodology, reliable and economical because of wide usage. SRM is unique while working as a generator and motor. Latest trend in power electronics made easy to use SRG directly as per the requirement to meet the design goals [2]. As a result of theoretical comparisons, the Switched Reluctance Generator (SRG) has a lot of advantages with respect to $\mathrm{PM}$ machines and AC machines, the controller design for the self-excitation mode of a SRG and the determinations of the variable parameters in a SRG controller.

\section{Analysis of Generators for Wind Energy Applications}

There are many kinds of generators used as wind turbine like Permanent Magnet Alternators, Synchronous Generators and Induction generators. Double-fed Induction and Reluctance Generators. Induction generators are used for very high power applications (in terms of large capacity), Permanent Magnet alternators are widely used for small capacity applications.

The Permanent Magnet Alternator has an advantage that a set of permanent magnet mounted on the rotor and rare earth magnets for efficient designs and has lot of disadvantage like domination of cogging torque, huge weight, magnetic circuit issues and high wind speed is required for full load operations.

A Synchronous Generator is an AC rotating machine whose speed is under a steady state condition is proportional to the frequency of the current in its armature. It has certain disadvantages like costly, complicated mechanical design, DC excitation is required and not suitable for variable speed applications.

Though the induction generators used for high capacity installation with few 
drawbacks like requires strong wind field for full load, during faulty condition response is poor, Rotor winding will have electrical losses.

A DFIG (Double-fed Induction Generator) is widely used in wind power generation. Stator is directly connected with grid and rotor is fed by voltage or current source inverter which has some drawbacks like high maintenance, span of turbine speed limits, rotor side converters operates at lower frequency.

A reliable wind turbine machine should have the features like-operates at lower wind speed with greater grid supports and responds quickly for wind variations. The turbine need to operate without any speed limitations, [3] Eliminates the cogging torque, very rapid response during faulty conditions, low cost manufacturing of generators and control system, eliminates rotor electrical losses and rotor winding, works at lower wind speed, etc. Switched Reluctance Machine will be the solution for the above and solves majority of issues in wind turbine applications.

\section{Switched Reluctance Machine Configuration}

Switched Reluctance machine has salient poles on both stator and rotor with concentrated winding on stator and no winding or no magnets on rotor. Due to the absence of winding in rotor of SRM, it can withstand high temperature and can rotate at very high speeds. The number of rotor poles, number of stator pole and number of phases decides the type of SRM as shown in the Figure 1 [4].

The torque ripple characteristics of SRM can be reduced by increasing the number of phases. However it is expensive to create such controllers to operate the SRM. Starting of SRM requires minimum of two phases and three phases the desired direction of rotation. An 8/6 pole, 4 phase SRM is proposed to develop a real time control system. An appropriate power electronic component is selected in accordance with the above motor as described above.

The electromechanical torque can be represented by the following equations.

$$
T_{e}=\frac{1}{2} i^{2} \frac{d L}{d \theta}
$$

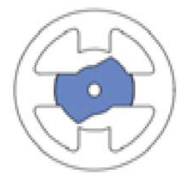

(a)

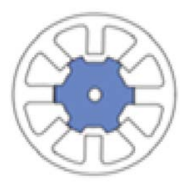

(c)

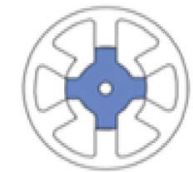

(b)

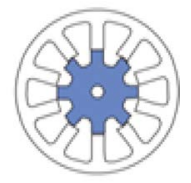

(d)

Figure 1. Various SRM geometrics. (a) 2 Phases 4/2 SRM; (b) 3 Phases 6 /4 SRM; (c) 4 Phases 8/6 SRM; (d) 5 Phases 10/8 SRM. 


$$
T=T_{e}-T_{L}=J(\mathrm{~d} \omega / \mathrm{d} t)
$$

where $v$ is stator voltage, $R$ is resistance in winding, $\lambda$ leakage magnetic flux, $T_{e}$ electromechanical torque, $T_{L}$ load torque, $\theta$ rotor position, $\omega$ speed, $J$ momentum of inertia.

SRM machine can be completely understood by the torque expression. The exact operation and its features can be identified from the torque expression with a requirement of the relationship between flux linkages and rotor position. These motors can be operated on all four quadrants [5]. Torque Versus speed characteristics can be achieved using inductance Verses rotor position of the SRM and the equivalent circuits can be formulated. The above parameters will be of good aid to design high performance controllers. The single phase controller finds exceptional usage with a disadvantage that its performance cannot match multiphase SRM.

Torque is produced by the movable part which has the tendency to shift to a position, where inductance of the exciting winding is maximized. Due to its simplicity, ruggedness, low cost and high energy conversion efficiency, SRM is used for various general purpose, adjustable speed and servo type applications [6]. The speed can be controlled by angle position control, phase chopping control, fixed angle pulse width modulation and variable angle pulse width modulation control.

The working of SRM explained in terms of the current passed through one set of winding of the stator and the torque produced by the tendency of the rotor to align with the excited stator pole. The generated torque direction is a function of the rotor position with respect to the energized phase and is independent of the direction of current flow through the phase winding. Continuous torque can be produced by logically synchronizing each phase's excitation with the rotor position.

Knowing the phase current (i) and voltage (v) of an energized phase of SRM, The flux linkage can be calculated using the following relationship (1)

$$
\psi=\int(v-i r) \mathrm{d} t
$$

Figure 2 illustrates the flux linkages verses stator current for various rotor positions of $8 / 6$ pole SRM. The voltage of each phase is proportional to the angular velocity and the rate of change of inductance with respect to rotor position can be understood from Equation (3). Electromagnetic torque $\left(\mathrm{T}_{\mathrm{e}}\right)$ produced by the SRM phase is directly proportional to the rate of change in co energy. It is realized that the motor creates positive torque in the direction of increasing flux linkage and negative torque in the direction of the decreasing flux linkage. Hence, it is essential to choose the proper rotor position to achieve the proper control of the SRM. It is necessary to design a hybrid controller in order to realize better control and speed response in all regions [7].

\section{The Proposed System}

The Figure 3 shows the block diagram of the proposed system. The wind energy 


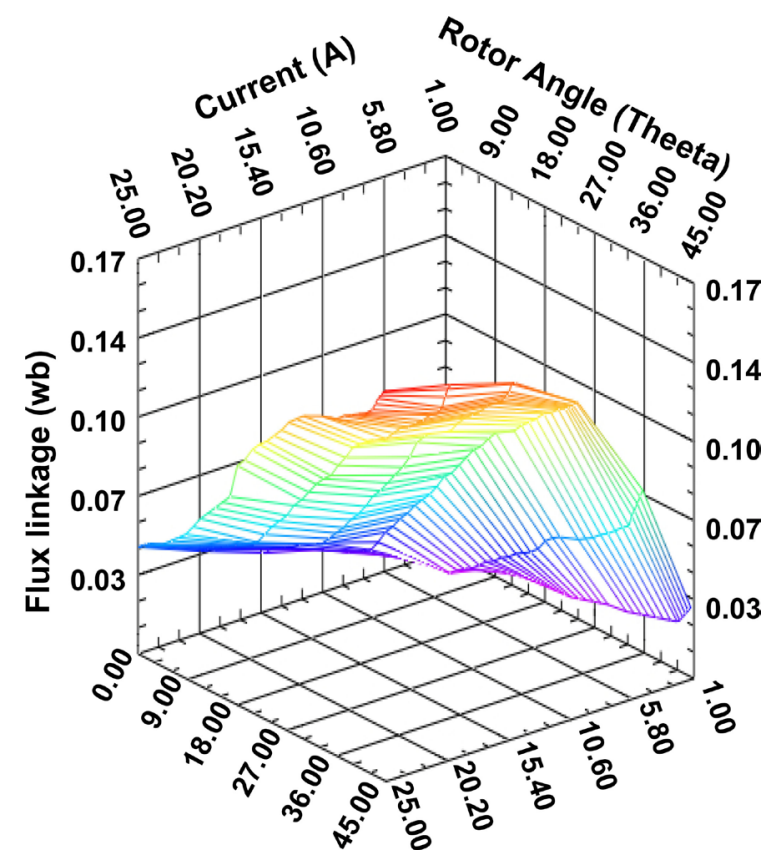

Figure 2. Characteristics of switched reluctance motor.

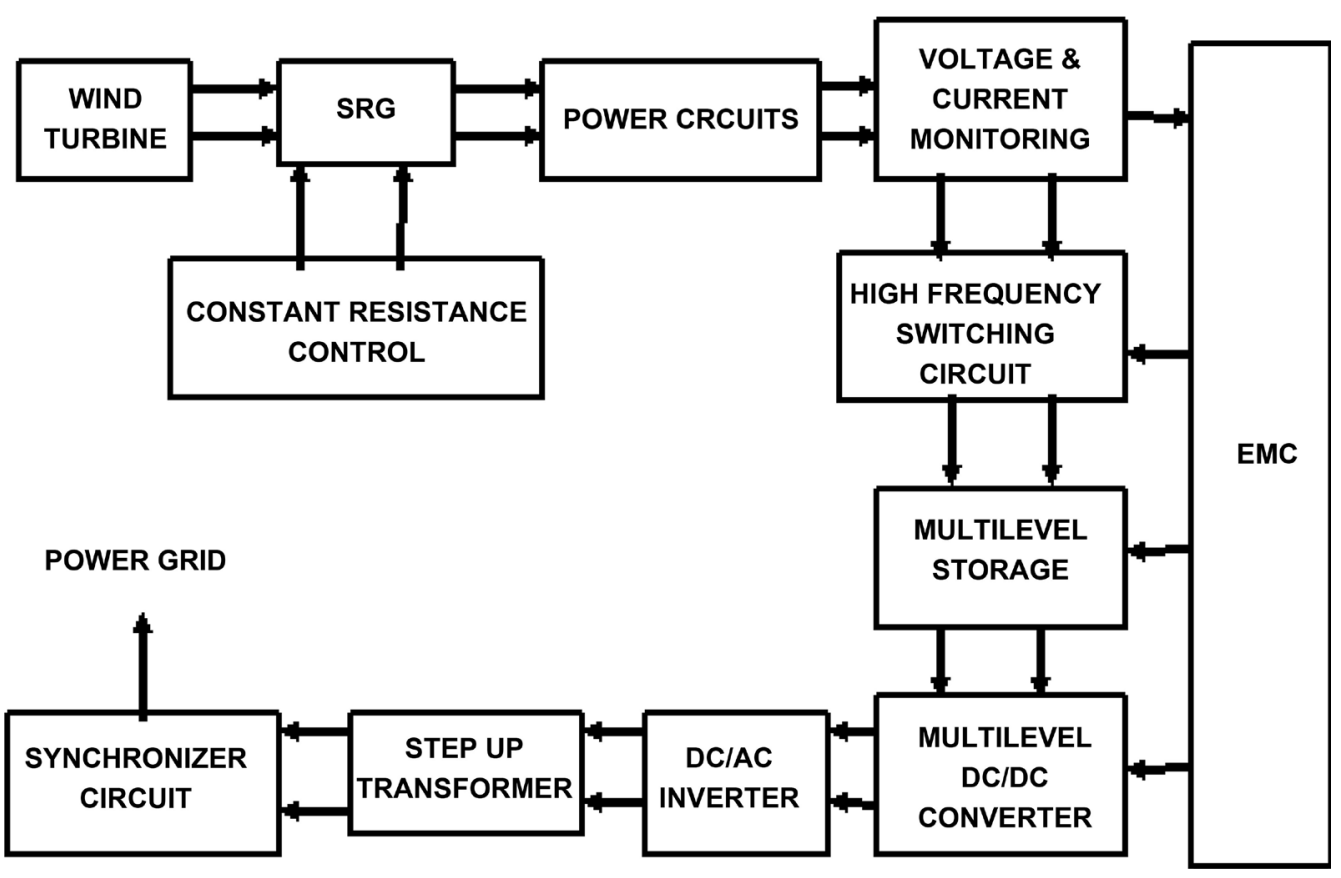

Figure 3. Block diagram of the proposed system.

is converted in to electrical energy by the SRG. It is controlled by the converter and control circuits. The output of SRG is connected to appropriate ultra capacitors in multi-level storage system. The embedded microcontroller is used for the selecting the storage system. Then the output of DC-DC converter is given to the DC-AC inverter. The ac voltage is step up by step up transformer and connected to the power grid through the synchronizer circuit. 


\subsection{Multi-Level Battery Charging}

Multi-level battery charging is implemented in this proposed scheme, as per the voltage from the turbine; automatically the appropriate storage device will be connected by the Embedded Micro controller. The micro controller receives the input from voltage and current sensing circuits and activates the storage connectivity between generator and storage. The storage is mainly used here for improving power quality for grid connectivity, this is essential because some uncertainties are always degrading the power quality issues in wind generation [8].

To analyze the real time issues, PIC 16F 877A Embedded Micro Controller is employed because of its unique industrial features. Port RB0-RB7 is connected to a 8 channel relay driver ULN2803 as shown in the Figure 4 . The relay driver is inexpensive and capable of driving 8 relays simultaneously with built in back EMF control. IC ULN2803 pin number 1 to 8 is the TTL input which is connected with embedded micro controller and pin number 11 to 18 is connected to 8 different relays, which activates multiple storage devices. Pin number 9 is ground and 10 become VCC.

In each $\mathrm{O} / \mathrm{P}$ Pin one relay is connected where the other end of the $\mathrm{O} / \mathrm{P}$ is connected to supply voltage. Ultimately we are switching only ground. Generally the relays will have NO/NC contact (SPDT). That NO/NC contacts will have one common one normally closed and one normally open. Before giving any supply to coil, Common will have contact with NC, when we offer supply to the coil common \& NO will get connected. These relays contacts can carry 7 Amps of $230 \mathrm{~V}$ A.C or 10 Amps of 28 D.C. The relay used in this proposed concept is electromagnetic attraction type with one potential free NO, NC contact whose resistance is $400 \mathrm{ohms}$, the coil current is $30 \mathrm{~mA}$, the operating voltage is $12 \mathrm{~V}$ and time taken for transition from NO to NC is approximately $60 \mathrm{mS}$. Figure 5 illustrates the multi-charging battery switching relay circuit.

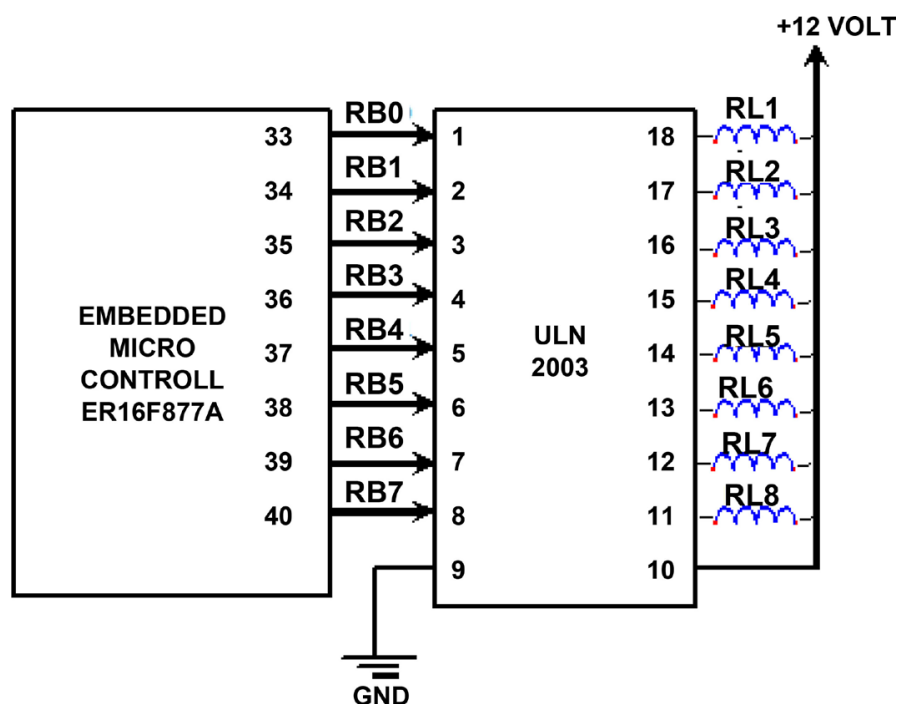

Figure 4. Multi channel relay driver. 


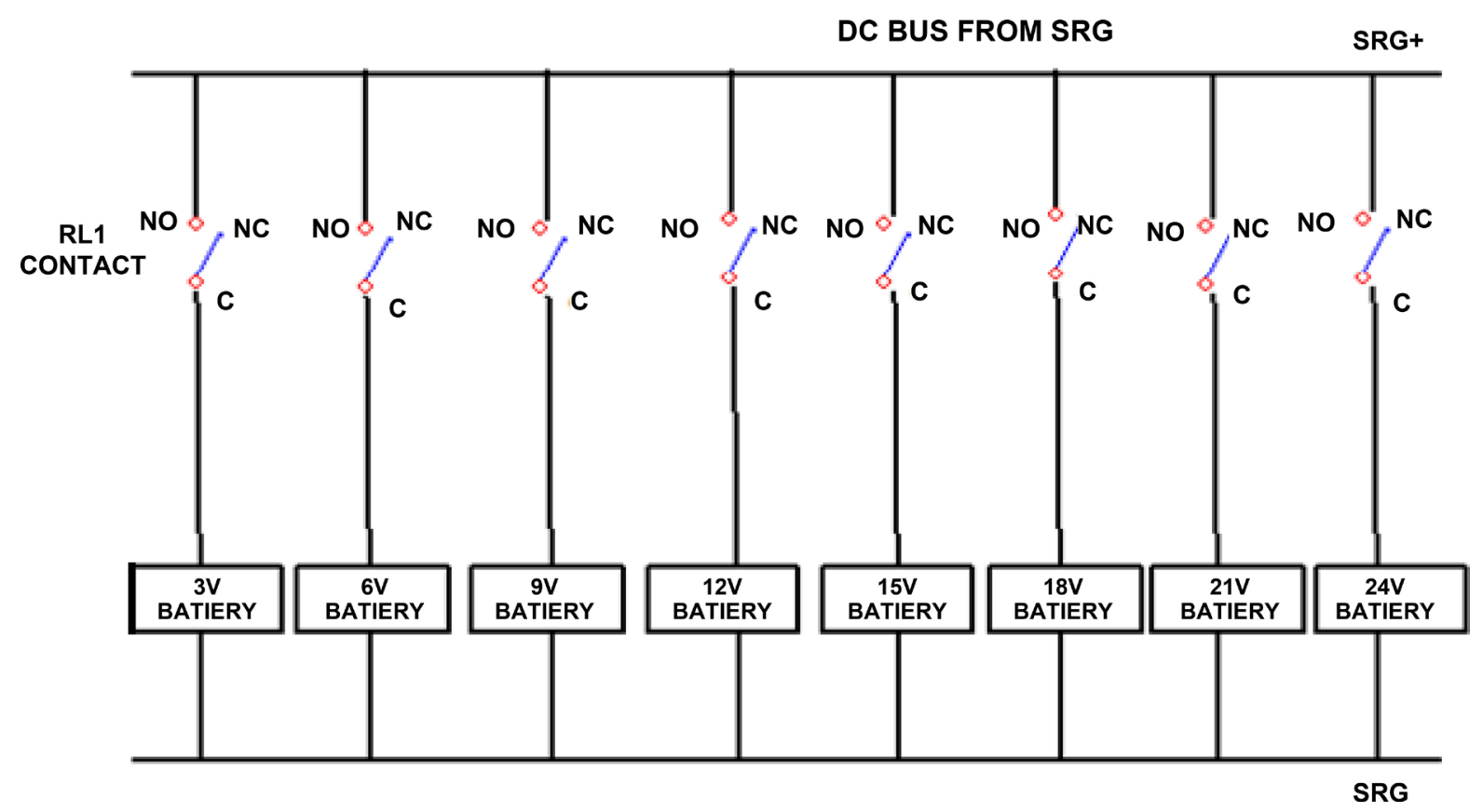

Figure 5. Multi charging battery switching relay circuit.

As per the photo voltaic voltage level embedded controller, will produce appropriate output from A-G at any time, it will switch only one output $3 \mathrm{~V}-\mathrm{A}$, 4.5V-B, 6V-C, 9V-D, 12V-E, 15V-F, 24V-G.

\subsection{DC-DC Converter}

As per proposed scheme, multilevel batteries charged separately will be connected to multi-level DC/DC converters. The proposed storage system must be selected according to the generator power. Storage devices like 3, 6, 9, 12, 15, 18, $21,24 \mathrm{~V}, 32 \mathrm{~V}$ are selected for the proposed scheme, all the storage devices then converted in to $24 \mathrm{~V}$ from their levels to meet common inverter as shown in the Figure 6. All the outputs of DC/DC converters are connected together with proper isolation devices. The inverter will provide $110 \mathrm{~V} / 230 \mathrm{~V}$ bus for auxiliary applications like metering to calculate various parameters received from the generator [9].

The inverter output will be fed to high voltage conversion using appropriate step up transformers to meet the grid requirements. The proposed scheme will give consistent output to the power grid irrespective of the small uncertainties due to the wind speed because, more concentration is given for power quality issues by implementing multi-level storage system are often called as BESS.

\subsection{Grid Synchronizer Circuit}

Power grids are complex networks in nature and responsible for infrastructure development to the nation. Highly efficient and reliable power grid is essential to the consumers, though more precautionary measures have been taken by opera- 


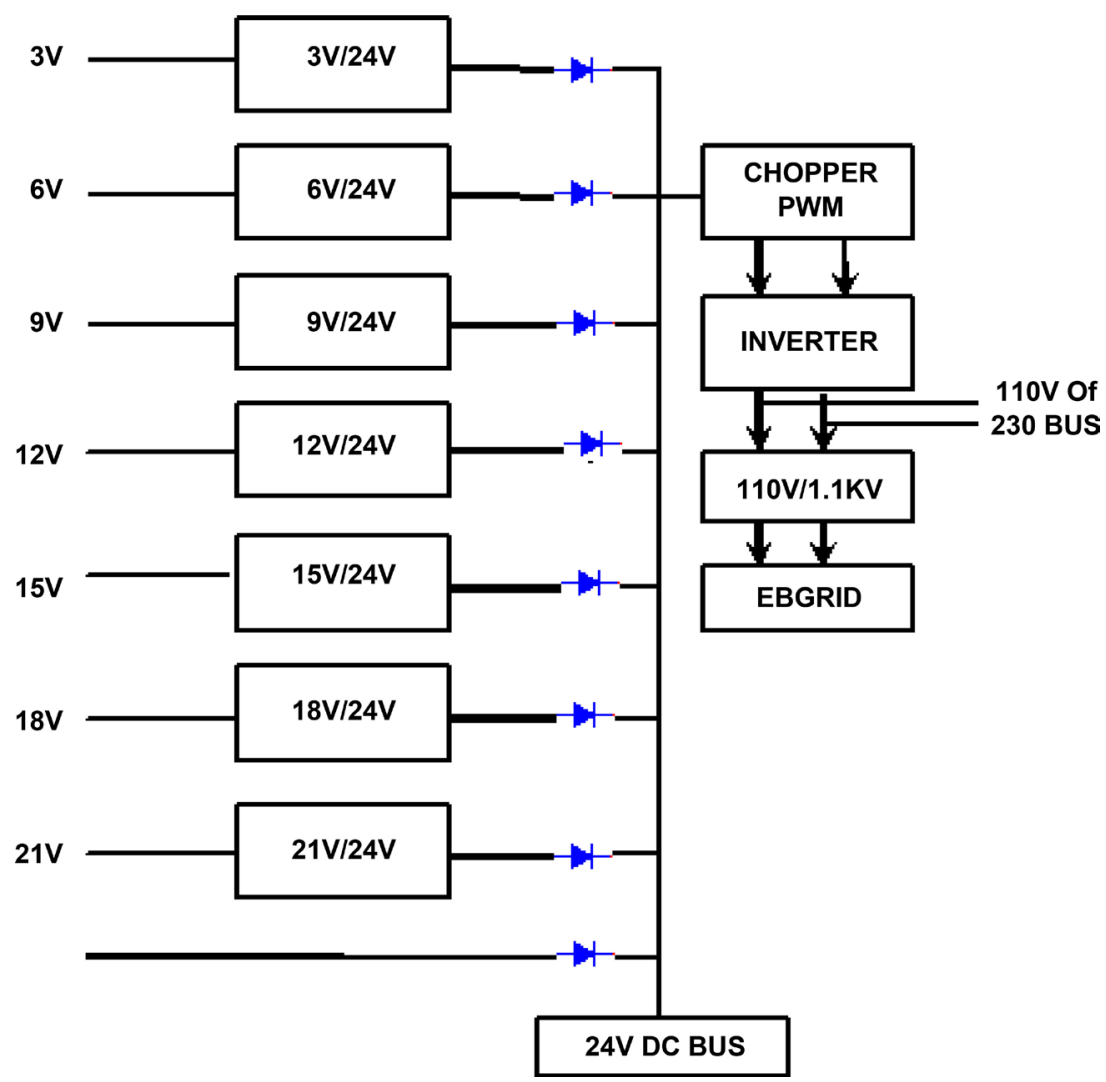

Figure 6. Schematic diagram of DC-DC converter.

tors, beyond that most of the power outages are caused by operators. This can be avoided by automatic control system to ensure reliability on grid networking. Synchronizer keeps the grid stability and provides excellent load support [10].

Synchronization is very essential to interconnect power generated by SRG to the electricity board common grid. Both the side uncertainty cannot be absolutely removed, but nowadays more concentration is focused towards power quality on the electricity board and the proposed system has the similar power quality improvement system. Synchronization of these two will not cause any problem to the power grid and to the generator. Being power generation is privatized and everyone is called as GENCOS, each GENCOS maintain their own standards for power quality matter, otherwise they will not be entertained for grid connectivity. These types of interconnection between GENCOS are called as distributed power generation.

The term synchronization mechanism works out with the concept of comparing two voltages, frequencies and phase sequence, one set of voltage and frequency from electricity board grid and other become the local generator (SRG COGEN), in common practice by keeping the EB voltage, frequency and phase sequence as constant and the COGEN inputs will be altered according to it. In general current transformer are used to measure individual current contribution by EB and GENCO, if anyone found not supporting to the grid, then the de- 
synchronization to be done to avoid over loading. Synchronization makes one common bus and there by possibilities for stepped up and down according to the requirement of transmission and distribution as shown in the Figure 7.

Voltage is measured using potential transformer and fed to appropriate signal conditioning circuit, current is measured using CT and applied to signal conditioning circuit and phase sequence is found using OPAMP based Zero Crossing Detectors (ZCD) with the help of PT. The frequency is measured using PT as an input, applied to appropriate Schmitt triggers, F/V converter and fed to microcontroller. All these data will be fed to embedded controller for further conversion and applied to the computer for accurate comparison to energies switchgear as shown in the Figure 8.

\subsection{Flow Chart and Scheme for Bus Synchronization}

Figure 9 shows the flow chart for bus synchronization. The synchronizing mechanism clearly indicates that first comparing V1 $=\mathrm{V}$. If true, it compares frequencies F1 and F2. If true, it compares zero cross detectors 1 and 2. If true, it displays both source are synchronized. Else not synchronized.

\section{Experimental Setup}

The Figure 10 shows the experimental setup of the proposed with hardware and

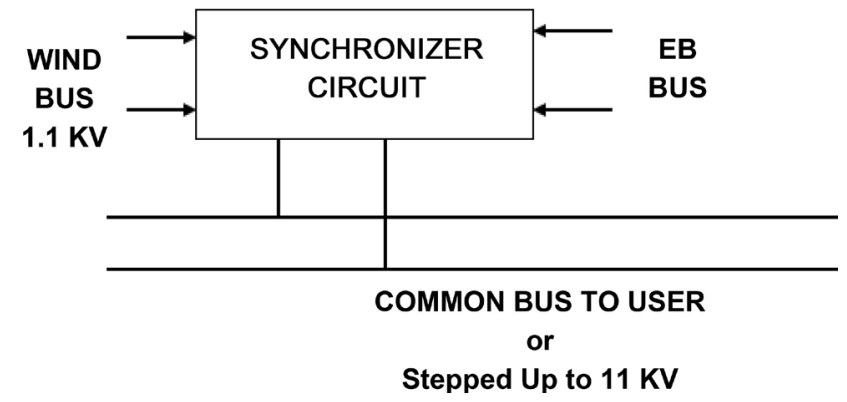

Figure 7. Bus synchronization.

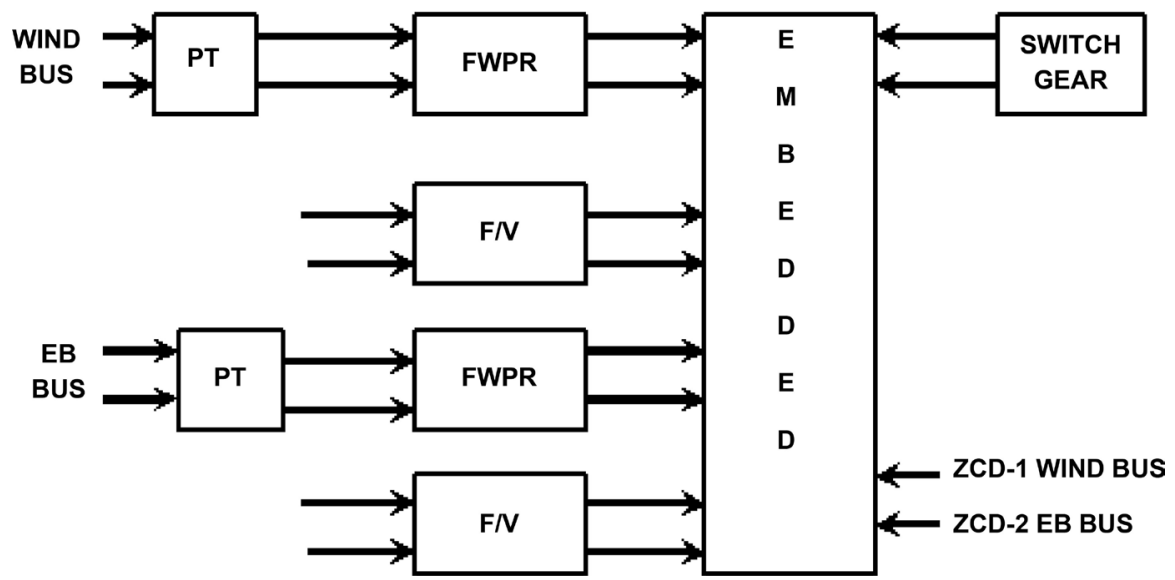

Figure 8. Block diagram of bus synchronizer. 


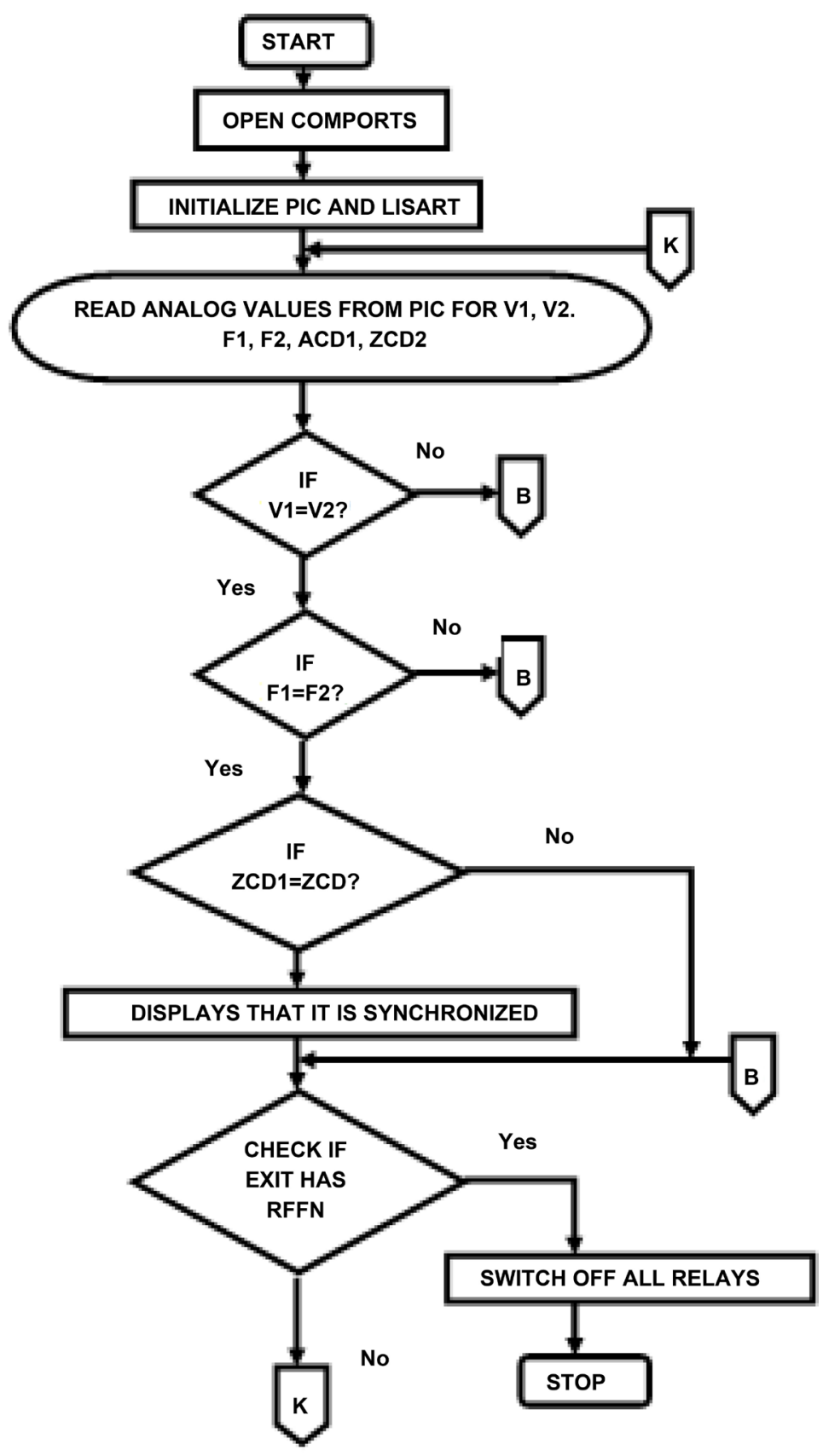

K = Exit or Restart

$\mathrm{B}=$ Condition for synchronization

Figure 9. Flow chart for bus synchronization.

software, while generator off state with Power Quality indicator shows the grid value.

The Figure 11 shows the experimental setup of the proposed with appropriate hardware and software, while generator running with external wind source. The graph indicates generator voltage, current and PQ output. The power Quality is improved using large volume of super capacitors for rapid response during ab- 
normal inputs and short time fault conditions. Super capacitors can replace regular storage devices like batteries because; it doesn't require any maintenance, good life span and nearly infinite charging cycle.

\section{Results and Discussion}

The real time data acquiring system using visual basic software is developed with data logger, the important parameters like generator output, inverter output, relay status, graphical representation of input/output characteristics and animated wind turbine movement is done in the software. Without input/output conditions, with software initialization the output is obtained.

Figure 12 shows voltage output from generator and subsequent inverter output with no load the graph shows the characteristics of input/output and On Screen Data Logger (OSDL). The output relay status shows the $12 \mathrm{~V}$ battery is ready to charge because the voltage is greater than $6 \mathrm{~V}$ and less than $25 \mathrm{~V}$. The voltage output from generator and subsequent inverter output with no load. The Figure 13 shows the characteristics of input/output and On Screen Data Logger (OSDL). The output relay status shows the $12 \mathrm{~V}$ battery is ready to charge. The

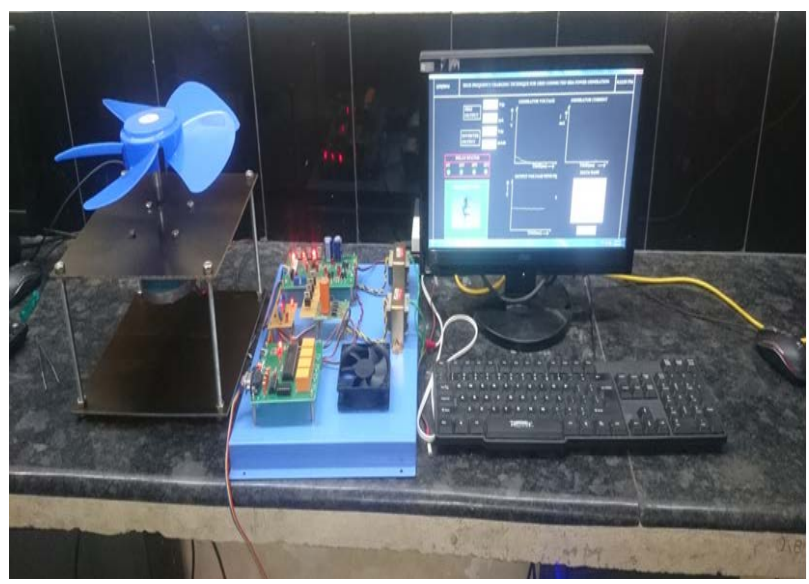

Figure 10. Experimental setup generator off condition.

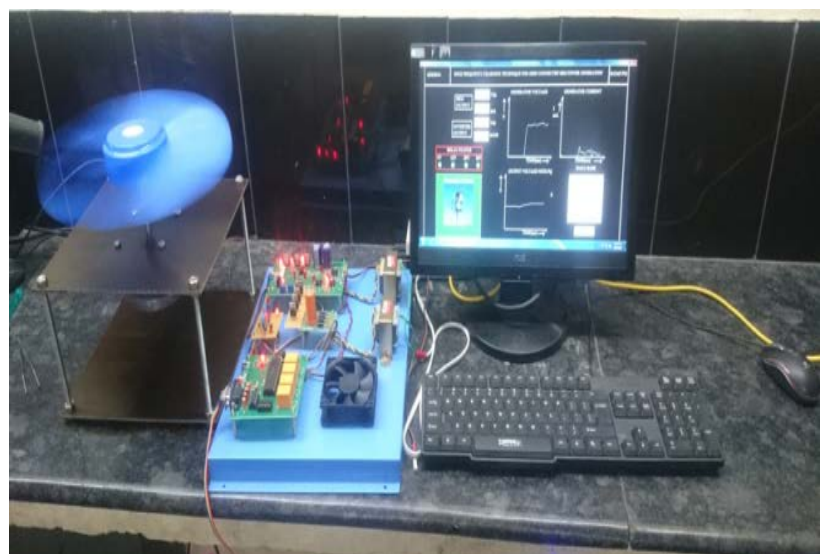

Figure 11. Experimental setup generator running condition with air blower. 


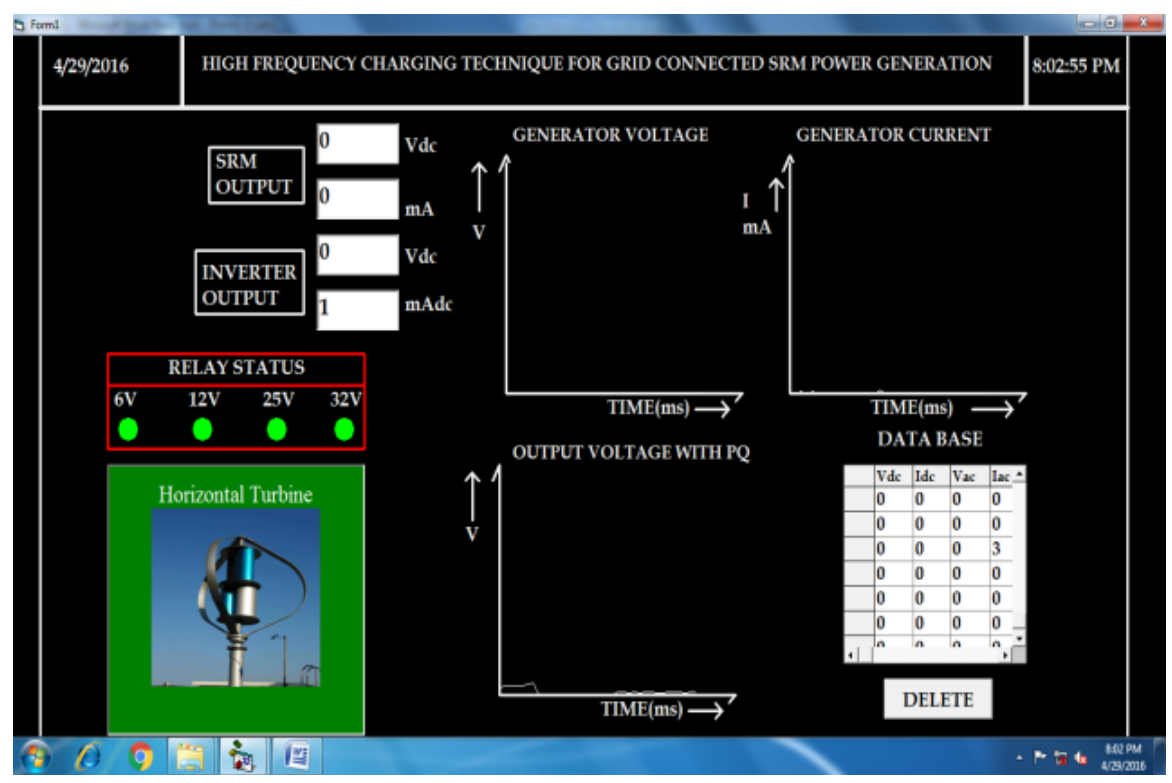

Figure 12. Real time analyzer without load.

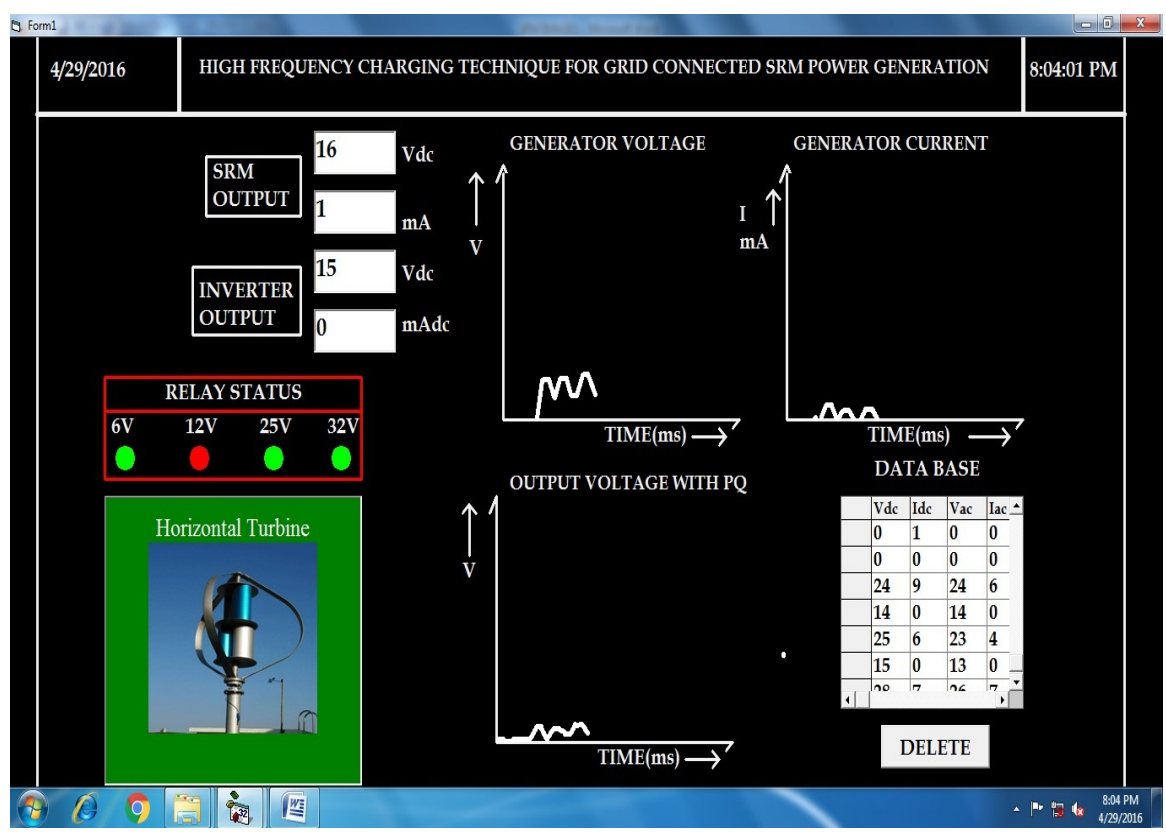

Figure 13. Real time analyzer with output voltage Selection relay.

Figure 14 shows the voltage is greater than $32 \mathrm{~V}$. Now this is with load. OSDL shows the real time values.

\section{Conclusion}

In this paper, High Frequency Switching based grid connected SRM generator is analyzed for real time application with necessary hardware and associated software. A multiple relay switching technology based on the generator voltage is implemented to harvest the energy at any level of voltage which intern charges 


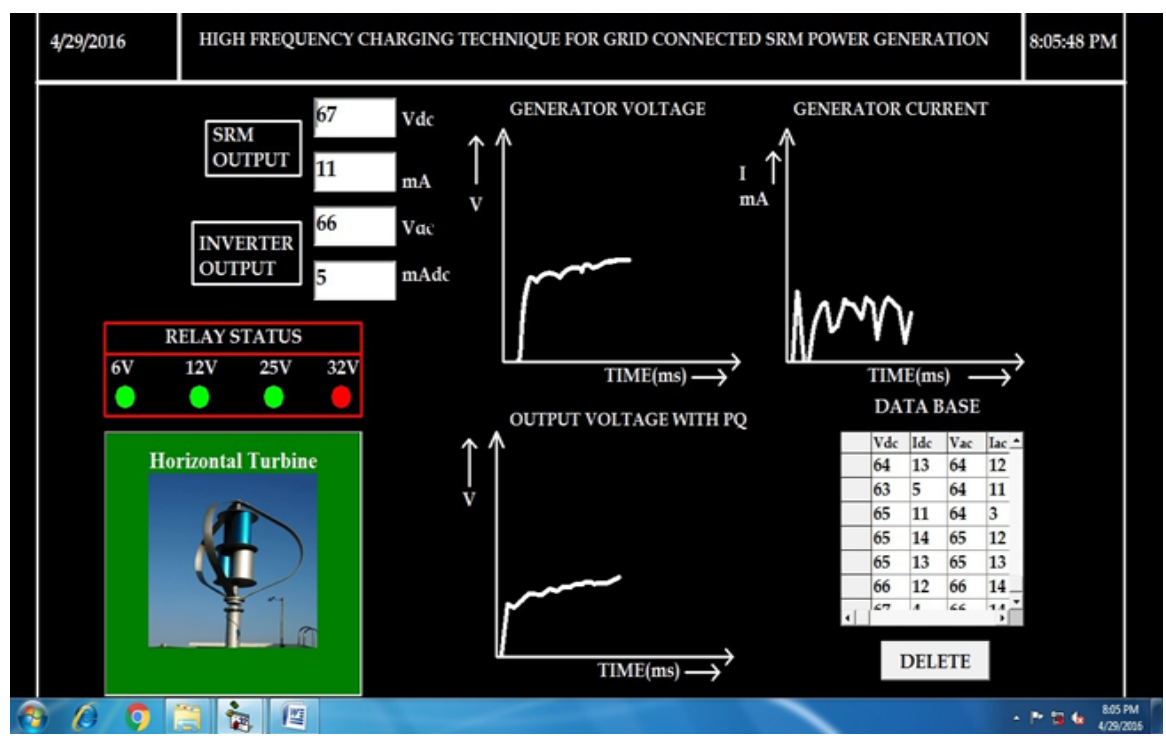

Figure 14. Real time analyzer with load and output relay selection.

super capacitors of various values is introduced in this proposed system. Irrespective of the fluctuations of the generator output, grid connecting voltage becomes constant because of the super capacitor used to improve power quality. The concept is fully evaluated and found suitable for real time applications. The real time parameters are recorded for analysis to improve efficiency of the whole system.

\section{References}

[1] Miller, T.J.E. (2001) Electronic Control of Switched Reluctance Machines. Newnes, Oxford.

[2] Krishnan, R. (2001) Switched Reluctance Motor Drives Modeling, Simulation, Analysis, Design and Applications. CRC Press, London.

https://doi.org/10.1201/9781420041644

[3] Yu, S.Y., Zhang, F.G., Lee, D.-H. and Ahn, J.-W. (2015) High Efficiency Operation of a Switched Reluctance Generator over a Wide Speed Range. Journal of Power Electronics, 15, 123-130.

[4] Nassereddine, M., Rizk, J. and Nagrial, M. (2008) Switched Reluctance Generator for Wind Power Applications. International Journal of Mechanical, Aerospace, Industrial, Mechatronic and Manufacturing Engineering, 2, 583-587.

[5] Arifin, A. and Al-Bahadly, I. (2011) Switched Reluctance Generator for Variable Speed Wind Energy Applications. Smart Grid and Renewable Energy (SGRE) Scientific Research, 2, 27-36.

[6] Anekunu, A.Y. (2015) Control of Switched Reluctance Generator for Wind Energy Applications. International Journal of Advanced Engineering Research and Technology (IJAERT), 3, 290-295.

[7] Chang, Y.C. and Liaw, C.M. (2008) On the Design of Power Circuit and Control Scheme for Switched Reluctance Generator. IEEE Transactions on Power Electronics, 23, 445-454. 
[8] Chen, J., Chen, J.W. and Gong, C. (2013) Constant-Bandwidth Maximum Power Point Tracking Strategy for Variable-Speed Wind Turbines and Its Design Details. IEEE Transactions on Industrial Electronics, 60, 5050-5058. https://doi.org/10.1109/TIE.2012.2225401

[9] Shen, M.S., Peng, F.Z. and Tolbert, L.M. (2008) Multilevel DC-DC Power Conversion System with Multiple DC Sources. IEEE Transactions on Power Electronics, 23, 420-426. https://doi.org/10.1109/TPEL.2007.911875

[10] Hasanien, H.M. and Muyeen, S.M. (2012) Speed Control of Grid-Connected Switched Reluctance Generator Driven by Variable Speed Wind Turbine Using Adaptive Neural Network Controller. Electric Power Systems Research, 84, 206-213.

https://doi.org/10.1016/j.epsr.2011.11.019

Submit or recommend next manuscript to SCIRP and we will provide best service for you:

Accepting pre-submission inquiries through Email, Facebook, LinkedIn, Twitter, etc. A wide selection of journals (inclusive of 9 subjects, more than 200 journals)

Providing 24-hour high-quality service

User-friendly online submission system

Fair and swift peer-review system

Efficient typesetting and proofreading procedure

Display of the result of downloads and visits, as well as the number of cited articles

Maximum dissemination of your research work

Submit your manuscript at: http://papersubmission.scirp.org/

Or contact cs@scirp.org 